\title{
A Summer Program to Attract Potential Computer Science Majors
}

\author{
Scott Vandenberg, Sharon G. Small, Meg Fryling, Robin Flatland, MaryAnne Egan \\ Computer Science Department \\ Siena College \\ vandenberg, ssmall, mfryling, flatland, maegan@siena.edu
}

\begin{abstract}
Computer Science (CS) is not taught in enough high schools thus many students arrive at college or university knowing little about it and often do not consider taking a CS course during their first year. At the same time, we encounter many college or university juniors and seniors who, while taking their first CS course, discover an aptitude and interest, at which point it is too late. We describe an innovative one-week residential summer program designed to educate non-computer science majors, before their second year of college or university, about the field's many areas and long-term prospects. The program has succeeded at encouraging undecided students to major or minor in CS and thus somewhat ameliorates the lack of CS in K-12 education and furthers the conference goal of "CS For All".
\end{abstract}

\section{KEYWORDS}

CS Summer Program, Recruitment, Retention, CS Education, Outreach, Computer Science Majors, Non-majors, STEM

\section{ACM Reference format:}

S. Vandenberg, S. G. Small, M. Fryling, R. Flatland, M. Egan. 2018. A Summer Program to Attract Potential Computer Science Majors. In Proceedings of SIGCSE '18: The 49th ACM Technical Symposium on Computer Science Education, Baltimore, MD, USA, Feb 21-24, 2018 (SIGCSE'18), 6 pages. https://doi.org/10.1145/3159450.3159562

\section{INTRODUCTION}

Many college and university-level Computer Science (CS) faculty worldwide have encountered the following situation: A highperforming $3^{\text {rd }}$ - or $4^{\text {th }}$-year student in an introductory CS course approaches you after class one day and says, "I'm really enjoying

Permission to make digital or hard copies of all or part of this work for personal or classroom use is granted without fee provided that copies are not made or distributed for profit or commercial advantage and that copies bear this notice and the full citation on the first page. Copyrights for components of this work owned by others than the author(s) must be honored. Abstracting with credit is permitted. To copy otherwise, or republish, to post on servers or to redistribute to lists, requires prior specific permission and/or a fee. Request permissions from Permissions@acm.org.

SIGCSE '18, February 21-24, 2018, Baltimore, MD, USA

(C) 2018 Copyright held by the owner/author(s). Publication rights licensed to ACM. ACM 978-1-4503-5103-4/18/02 ...\$15.00

https://doi.org/10.1145/3159450.3159562 this class and I'm doing very well in it. I wish it wasn't too late to change my major. Why didn't somebody tell us about this field earlier?' In many cases they are also out of time to complete a minor, but they still want to take as many CS courses as they can. We encountered this often enough at Siena College, a fouryear post-secondary liberal arts college, that we decided to try to do something about it. A program similar to ours could be implemented at any college or university offering a typical fouryear CS degree, and references to "college" should generally be interpreted as "college or university".

It is well known that a large percentage of secondary schools in the United States and other countries offer little in the way of real CS education [3]. In addition, very few colleges and universities explicitly require CS, though some (including Siena) do allow certain CS courses to count as courses in a required area such as quantitative reasoning or analysis. Thus, while a large percentage of college or university freshmen will be taking a mathematics course (a worthwhile thing, to be sure), relatively few of them will be taking a CS course.

In order to help a certain cohort of students understand the nature and possibilities of the field, we hypothesized that exposing them to the field prior to their sophomore year might help them end up "in the right place" by allowing them to make an informed decision about a major or minor with enough time left for them to do something about it. Having them take a course would be ideal, but we needed something to get them into that first course, at which point we have an opportunity to give them a more complete picture of CS. Our program exclusively targets students who have not declared CS as a major, that is we do not invite CS majors to apply to the program.

We have run this program three times (summers 2015-2017) and will be running it at least two more times. More complete results will be reported in several more years, when we know graduation and retention rates, but we believe these early results are very encouraging and warrant dissemination so that others may be able to run similar programs: waiting any longer may result in more students missing out on their true calling. The program is being run in the setting of a 4-year liberal arts college with approximately 3000 total full-time undergraduate students. We have a relatively healthy CS major for a liberal arts college, with about 150 majors total and 13 tenure-track faculty. Siena College also has a successful School of Business, unusual for a liberal arts college. Our department teaches, in addition to a typical CS curriculum, a number of Information Systems (IS) courses. We also offer an IS minor and certificate. 
The next section of this paper reports on related work, followed by a section describing the summer program itself, with enough detail to be replicable. Section 4 describes our outcomes based on the first two years of the program, Section 5 describes our next steps, and the final section contains conclusions and lessons learned.

\section{SUMMER PROGRAMS - RELATED WORK}

There appears to currently be very little work in summer recruitment efforts for students entering their first and second year of college. There are instances of programs that do reach out and educate students while still in high school and there are bridge programs to improve college readiness. There are also programs that focus on retention by offering research opportunities early in the student's college career: freshman and sophomore years to students who are CS majors [9]. Since the program is so unique in its combination of content and cohort served, our goal here is to present it and demonstrate that it works, not to say that it works better or worse than other programs designed for very different cohorts.

A program most similar to ours is the IMPACT program [2] run annually at Siena College in the Fall semester of each year. High school juniors who are strong in mathematics, and their teachers are recruited to attend the day-long event. Students spend the day learning about CS topics through interactive sessions. This program is similar in goal to our work. The distinctions are that IMPACT is for high school juniors while our summer program is for incoming college freshmen and sophomores, and ours is a 1-week residential program.

Programs offered over the summer tend to be bridge programs, focusing on improving a student's college readiness. The National Center for Postsecondary Research evaluated [1] eight of these types of programs in Texas. These programs all included accelerated instruction in math, which should improve course performance in typical required math courses for the CS major potentially improving retention for students that participated in these types of programs.

Research programs are also being offered to students earlier in the CS program, freshman and sophomore years, in an effort to improve student retention. One such program funded by the National Science Foundation at Appalachian State University [9] has shown some promising results. In their latest reported year $79 \%$ of the students indicated that their participation in the research program was either Very Helpful (61\%) or Helpful (17\%) with only $22 \%$ indicating that it was Little Helpful.

Markowitz [7] describes a general summer science program with positive results, and [4] describe positive long-term results of a summer science program, but these are designed specifically for high school students, not for rising sophomores and freshmen within the college as ours is, and are not specific to CS.

These other efforts gave us encouragement that a summer program could be successful, but finding no evidence that others had tried what we were planning, we had no real model to go by, so we devised the program described in the next section.

\section{OUR SUMMER PROGRAM}

We first describe how we select students for the program, followed by a description of the week's activities and some important logistical details. Data we gathered ${ }^{2}$ from our college before starting this program indicated that $65 \%$ of undecided science majors ended up not obtaining a degree in a STEM field (either because they did not graduate or they changed to a nonSTEM major). Of incoming science students with a declared major, $47 \%$ did not obtain a STEM degree. Furthermore, a large portion of both of these groups had not been previously exposed to CS. At the same time, other data from our college indicated that significant numbers of undecided students from non-science fields might have the aptitude to succeed in CS, based on their Math SAT scores being higher than the average Math SAT score of CS majors. Obviously this is only one limited metric, but it encouraged us enough to hope that there were enough undecided students in the college as a whole who had the quantitative, analytical, and symbolic reasoning proficiency, and possibly the interest, to succeed in CS.

\subsection{Student Selection}

The program is designed for about 18-24 students per year. We start by identifying undecided (students who have not declared a major yet) rising sophomores near the end of the freshman year (typically in March). The motivation here is that undecided students are more likely to consider something new, and we want to get them before it's too late for them to complete the major. We target students from all areas of the college (science, liberal arts, and business). Most of the seats in the program are filled in this way. Each year, however, we have had room for a number (5-7) of incoming freshmen to attend the program. All invited students are full-time students at Siena College.

We obtain academic records and contact information for current undecided freshmen (rising sophomores) from our institutional research office. Specifically, we request cumulative GPA and test scores, if available, for the SAT math test and/or the ACT math test. We then invite the subset of students from that list who have a GPA of at least 2.8 and a math SAT score of at least 540 (ACT equivalent about 21). These criteria are used for one main reason: there is an academic threshold that demonstrates a student's ability to be successful in CS and it would be a disservice to recruit a student into CS who is unlikely to succeed. We are also able, if we think it necessary, to examine the students' complete academic records online to help us decide whether to extend an invitation to apply. These invitations go out in mid-to-late April, and we give them several weeks to respond. The invitations to rising sophomores are sent in three ways: via email to the student's college account, via paper to their campus post office box (if they live on campus), and via US mail to their home address (whether they live on campus or not).

${ }^{2}$ Data cited are for graduation years 2014-2017 
The application process for the students is online and brief (contact information, housing preferences for the program, brief response about why they are interested, and any other students they may know who may have a similar interest - just in case we missed someone good in our process). After the deadline, we send out acceptance notifications. During the first three years of the program, we have accepted $100 \%$ of the sophomores who applied (this is unsurprising, because we would not have invited them to apply if we didn't think they would benefit from the program). The acceptance notification requires the students to confirm (or reject) their attendance at the program; we also threaten to penalize their college financial account by $\$ 75$ if they confirm attendance but then don't show up. This is to ensure that we don't end up with empty seats that could have been filled by someone else interested in the program. (In practice we have not had to enforce this; our only no-show so far was a student who never bothered to show up for college at all.)

\begin{tabular}{|l|c|c|c|}
\cline { 2 - 4 } \multicolumn{1}{c|}{} & Year 1 & Year 2 & Year 3 \\
\hline Sophomore Pool & 180 & 179 & $\begin{array}{c}394 \text { (65 Biology } \\
+159 \text { Undecided } \\
+170 \text { Business })\end{array}$ \\
\hline Sophomore Invites & 83 & 85 & $\begin{array}{c}155 \text { (35 Biology } \\
+72 \text { Undecided } \\
+48 \text { Business })\end{array}$ \\
\hline Sophomore Attended & 15 & 13 & 18 (8+5+5) \\
\hline Freshman Undecided & 225 & 207 & 124 \\
\hline Freshman Invites & 85 & 96 & 68 \\
\hline Freshman Attended & 5 & 7 & 52 \\
\hline Total Invites & $\begin{array}{c}168(82 \\
\text { female })\end{array}$ & $\begin{array}{c}181(98 \\
\text { female })\end{array}$ & $223(113$ female) \\
\hline Total Attended & 19 & 20 & 23 \\
\hline \% Females Attended & 53 & 55 & 52 \\
\hline
\end{tabular}

Table 1: Program Invite, Application, Participation Data, Years 1-3

We have had room, at least the first 3 years, for all the interested rising sophomores, with some space left over for incoming freshmen, who are invited separately (and after the rising sophomores, since we normally don't know until after May 1st who will be attending in the fall). In year 3 (Spring 2017), we expanded the list of invited rising sophomores to include selected biology majors and business majors who may be looking for a second major or a new major, or a minor. In part this was done because this is where we find students at Siena College who later discover they are "in the wrong major". We also expanded in this direction because the number of undecided sophomores and freshmen were both decreasing (Table 1). This expansion was done with the enthusiastic support of the relevant academic administrators (department chairs and deans): while the program certainly is a recruitment tool, and everyone knows that, we have been careful to structure it in such a way as to educate and raise awareness, and we are always careful to emphasize that our purpose is to help the students make an informed decision, not to indoctrinate them. Our biology department, for example, is highly selective, and thus has a relatively low retention rate, with over $24 \%$ of students not graduating from the college, and another $44 \%$ not graduating in a STEM field. This is one potential area for finding students who may find a home in CS and, if we find them early enough, many still graduate in four years.

The undecided incoming freshmen are again identified for us by our institutional research department, with some help from admissions, in early-to-mid May. In the case of these freshmen, we do not send out paper invitations to apply. Instead, we send two emails, one to their college account and one to the contact email address listed on their college application. We narrow down this list similarly to how we limit the rising sophomores list, but instead of cumulative college GPA we use their high school grade average, and require it to be at least a B or 3.0. Freshmen are invited to apply in late May or early June, and are again given a few weeks to respond.

Table 1 contains some invitation/application/attendance numbers for the first three years of the program. One interesting trend is the diminishing number of undecided students, which was one reason we expanded the recruitment of rising sophomores to include students from selected majors. We are also encouraged by the percentage of women (over $50 \%$ ) participating in the program: this is a historically underrepresented group in CS.

\subsection{Program Structure}

The main goal of the program is to expose the students, via specific, targeted activities, to the thinking and problem-solving that goes into CS. The schedule of activities for the program in Year 2 (2016) is shown in Figure 1. The schedules for Years 1 and 3 are similar. We have omitted faculty names and replaced them with numbers. As you can see from the figure, this is not a "programming boot camp", nor is it just a compressed version of an Introduction to CS (CS0 or CS1) course. It is a combination of computer-based and non-computer-based activities, as well as panel discussions, that together give a fairly complete picture of the kinds of thinking and problem-solving involved in CS. This does include some programming, but it also includes web page design, game design, work with finite automata, simulations of sorting algorithms, visualizations of data compression, etc.

All sessions involve all participants and are handson/interactive. Each session is led by 1 or 2 tenure-track CS faculty: notice from Figure 1 that 9 different faculty participated in this way. This program can and should not be a "one-person show". It is too much for one person to do, and it is beneficial for the students to see a variety of faculty, thus a variety of ways 
of thinking about problems and thinking computationally. Of course, we could have done it with fewer faculty, but we are fortunate to have a very participatory group!

The morning sessions are all "unplugged" in the sense that the students do not use computers for anything. Students sit at round 4-6 person tables (no computers at the tables) and typically work in groups on activities that illustrate the kind of thinking and problem-solving involved in CS. Some of these activities were drawn from existing literature such as CS Unplugged $^{3}$, and others are "home-grown".

\begin{tabular}{|c|c|c|c|c|c|}
\hline & Mon 29 Aug & Tue 30 Aug & Wed 31 Aug & Thu 1 Sep & Fri 2 Sep \\
\hline $\begin{array}{l}\text { 9AM - } \\
\text { noon }\end{array}$ & $\begin{array}{c}\text { Welcome } \\
\text { Introductions } \\
\text { Making it Fit: } \\
\frac{\text { Data }}{\text { Compression }} \\
\text { (Faciulty 1,2) }\end{array}$ & $\begin{array}{c}\frac{\text { Software }}{\text { Engineering }} \\
\frac{\text { and }}{\text { Tinkertoys }} \\
\frac{\text { (Faculty 2) }}{}\end{array}$ & $\begin{array}{l}\frac{\text { Computing }}{\text { Without }} \\
\text { Computers: } \\
\text { Models of } \\
\frac{\text { Computation }}{\text { (Faculty 5) }}\end{array}$ & $\begin{array}{c}\frac{\text { Mind Your }}{\text { Own }} \\
\text { Business: } \\
\text { Privacy, } \\
\text { Secrecy, and } \\
\text { Encryption } \\
\text { (Faculty 6) }\end{array}$ & $\begin{array}{l}\text { Discuss Movie } \\
\text { (Faulty 1); } \\
\text { Who's Next? } \\
\text { Putting Things } \\
\begin{array}{c}\text { in Order } \\
\text { (Faculty 9) }\end{array}\end{array}$ \\
\hline $12 \mathrm{pm}-1$ & \multicolumn{5}{|c|}{ Lunch } \\
\hline $\begin{array}{l}\text { 1PM - } \\
\text { 4PM }\end{array}$ & $\frac{\text { Time to Make }}{\frac{\text { Stuff: } 3 D}{\text { Printing }}}$ & $\begin{array}{l}\text { Put Yourself } \\
\text { Out There: } \\
\text { Makinga } \\
\text { Mobile Web } \\
\begin{array}{c}\text { Page } \\
\text { (Faculty 4) }\end{array}\end{array}$ & $\begin{array}{l}\frac{\text { Time to Play: }}{\text { Game }} \\
\frac{\text { Development }}{\text { using }} \\
\frac{\text { GameMaker }}{\text { (Faculty 3) }}\end{array}$ & 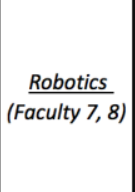 & $\begin{array}{l}\frac{\text { Joyful Noise: }}{\text { Making Music }} \\
\frac{\text { with Python }}{\text { (Faculty 1) }}\end{array}$ \\
\hline 4-6:30 & \multicolumn{5}{|c|}{ Free time/dinner } \\
\hline $\begin{array}{l}\text { 6:30PM- } \\
\text { 8:30PM }\end{array}$ & $\begin{array}{l}\text { Alumni Panel: } \\
\begin{array}{c}\text { Life after } \\
\text { College }\end{array}\end{array}$ & $\begin{array}{l}\frac{\text { Intern \& }}{\text { Research }} \\
\text { Panel: Life } \\
\text { at College } \\
\text { Beyond the } \\
\text { Classroom }\end{array}$ & $\begin{array}{l}\text { Faculty Panel: } \\
\text { Life at College } \\
\text { in and out of } \\
\text { Classroom, } \\
\text { Career } \\
\text { Opportunities, } \\
\text { etc. }\end{array}$ & $\frac{\text { Movie Night: }}{\text { TBA }}$ & $\begin{array}{c}\text { Have a great } \\
\text { weekend! }\end{array}$ \\
\hline
\end{tabular}

Figure 1: Summer Program Schedule, Year 2 (2016)

The afternoon sessions have the students on computers (using various lab rooms in our CS facilities). On the first day, for example, they use 3D printing software to design an object, which is printed out for them and given to them at the end of the week; the context of 3D printing can be used to learn about process and abstraction [5]. The GameMaker software package is used on the third day (game design can be used to teach computational thinking [8]).

The Robotics session on Thursday involves programming our department's robots (used also in our upper-level robotics course). The amount of actual programming done is minimal early in the week: they learn concepts, possibilities, and strategies the first 3 afternoons. Though some would consider much of what they do to be programming, they are not writing code in a general-purpose programming language until Day 4 and what they do there is mainly "fill in some blanks". On the last day, the afternoon activity involves simple programming by creating music in Python [6].

\footnotetext{
${ }^{3}$ http://csunplugged.org
}

The evening sessions are panel discussions. The first one is comprised of 4-6 CS alumni from Siena College who give brief introductions of what they have been doing after college, then answer questions from the participants. The second night's panel is structured similarly, but involves panelists who are current CS majors and have done some sort of internship or research activity. The faculty panel on the third night gives the faculty an opportunity to describe the CS curriculum briefly, advise students on what courses to take for a major/minor/etc., and to talk to them more about career and internship opportunities from a faculty perspective. Thursday's evening activity is a movie with some sort of CS theme, and there is no Friday evening activity.

In each of the years of the program so far, we have been fortunate to have been able to have two student assistants (CS majors) to help us out during the daytime sessions. They work with the participants to help them with concepts or problemsolving or (in the afternoon sessions) software and syntax issues. We believe it is good for the participants to see not just the faculty, but also their fellow students who are CS majors and can give them different perspectives on the field.

\subsection{Logistics}

At this point the reader may wonder how we convinced about 20 students each year to give up a week of their summer to do this. Of course, we hope it is because they have seen a sample program from a previous year and are intellectually stimulated enough to want to learn more. And that is genuinely the case with most of them. But we have added inducements. First, we hold the program the week before classes: students can simply return to campus and move in one week early (or commute if they live locally). College is a very fun place when you have no homework, and the students appreciate being able to move in early. We also offer them the option to stay in the dorms for the week even if they typically live off-campus: the intent is that this is a residential program.

We also do not want this program to cost the students anything, so their food and lodging are paid throughout the program, from Sunday dinner through Friday lunch (the students arrive Sunday to check in so we can get a full week of the program in). In addition, each student completing the program is given a $\$ 100$ stipend upon completion (full attendance required, though we have been a little flexible with genuine conflicts such as required freshman orientation activities). Practically, we have to be a little flexible for highly active students who may have legitimate conflicts with 1 or 2 sessions but will still gain value from participating. Currently the program is funded by the National Science Foundation; we address sustainability issues in Section 5.

At the end of Friday's activities, students can meet with a faculty advisor if they want to make any last-minute changes to their fall schedule, such as enroll in our Introduction to CS course (we reserve at least 8-10 seats for students from this program, spread among 4-5 sections, before "opening it up" again to everyone else). They may also speak with an advisor in 
more general terms, or they may plan a sequence of courses in CS that begins in the spring instead of the fall semester.

\section{OUTCOMES}

The results of the program, by several measures, demonstrate a great deal of success. Of course we realize these results are preliminary, since the program is only in its third year right now and the students who took it as rising sophomores in Year 1 will be seniors in Fall 2017. But the outcomes to date are very positive and have encouraged us to disseminate the ideas so that others can take advantage of them.

We have completed 2 years of the program, which means the participants from Year 1 have completed 4 semesters (2 years) since they experienced the program, and none have graduated. We have some interesting results based on course registrations post-program; major and minor declarations post-program; student survey feedback (a survey is administered at the end of the program); and grade data. We should note also that the program has a $100 \%$ completion rate through the first two years (no student dropped the program and only one student had attendance issues).

A basic outcome, of course, is that 20 students per year learn about CS earlier than they would have. But we would also like to know that they have decided, after the program, to continue on with more CS education. Table 2 shows the numbers of course registrations, minors declared, and majors declared for participants from Years 1 and 2 of the program (the number of courses is courses completed as of the end of spring semester 2017). From Table 2, we see that in each year, about $75 \%$ of the students took at least one additional CS course (and some of those declared a major or minor).

\begin{tabular}{|l|l|l|}
\cline { 2 - 3 } \multicolumn{1}{c|}{} & \multicolumn{1}{c|}{$\begin{array}{c}\text { YEAR ONE } \\
\text { (n=19) }\end{array}$} & $\begin{array}{c}\text { YEAR TWO } \\
(\mathrm{n}=20)\end{array}$ \\
\hline \# taking no more CS courses & 5 & 6 \\
\hline \# taking 1 CS course & 3 & 7 \\
\hline \# taking 2 CS courses & 2 & 5 \\
\hline \# taking 3 CS courses & 2 & 0 \\
\hline \# taking 4+ CS courses & 7 & 2 \\
\hline \# declared minors & 1 & 1 \\
\hline \# declared majors & 7 & 5 \\
\hline
\end{tabular}

Table 2: Participants Enrolling, Minoring, and Majoring in CS After the Program

As can be seen in Figure 2, overall, 31\% of the participants have declared a major in CS after their participation in the program. From Year 1, 37\% of the participants declared a CS major and from Year 2, 25\% (so far) have declared a CS major. All of these students were previously undeclared majors. The percentage of undeclared students who did not participate in the program but still declared a CS major is $2.3 \%$, so our program participants are much more likely ( $31 \%$ vs. $2.3 \%$ ) to declare a CS major. The numbers for declared CS minors from these same cohorts are also quite favorable: $5.13 \%$ of the participants declared a minor in CS versus only $1.64 \%$ of non-participating undeclared students.

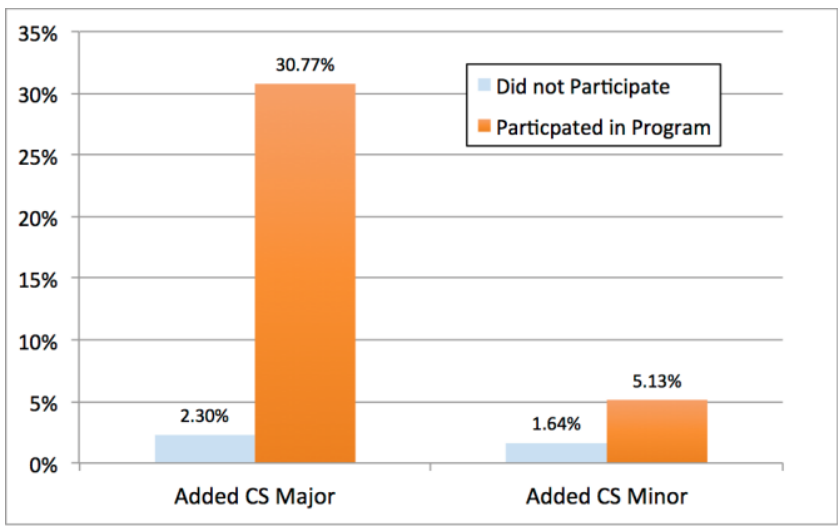

Figure 2: Major \& Minor Effects from Summer Program

Of course, one would hope that students accepting our invitation to the program would enroll in the major or minor at a higher rate than the group of all undecided students. But, as can be seen in Figure 3, we also compared the numbers of undecided students that added the CS major and minor in the four semesters after our program began to the four semesters before our program began. Both comparisons, which measure the proportion of students who were undecided at some point during those four semesters and then switched to CS during those four semesters, show a significant improvement in the percentages of undecided students who declared new CS majors and new CS minors after we began our Summer Program.

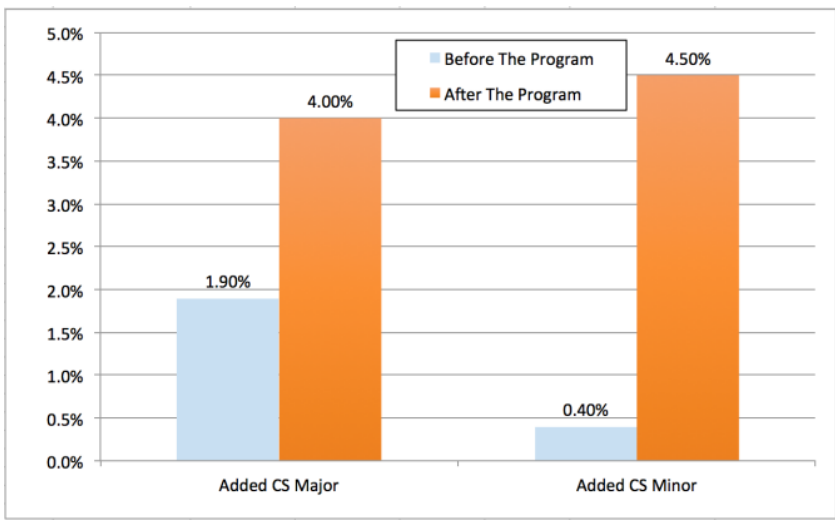

Figure 3: Major \& Minor Effects: \% of Undecided Students Adding CS Major/Minor for the Four Semesters Before and After the Summer Program was First Offered

In addition to the very positive enrollment results, we have some very valuable and favorable feedback from surveys. We administered online surveys, both pre-program and postprogram, in Years 1 and 2. The basic results from these surveys 
indicate the students enjoy the program and find it worthwhile and helpful in career exploration.

More specifically, participants indicated that they enroll in the program to learn more about CS, move in early, help decide on a major, and to have fun. The post-surveys indicate the students had a very positive and educational experience, that they appreciated the breadth of topics offered, they liked the faculty, and they found the panels very worthwhile. Half of the participants, at the end of program, "agree" or "strongly agree" that they are considering majoring in CS (measured on a 5-point Likert scale from "strongly agree" to "strongly disagree"). In addition, about two-thirds are considering a minor. Nearly all participants found the program interesting and would recommend it to others, thought it encouraged critical thinking, and increased their interest in CS.

Finally, in examining grades, we wanted to see how these participants have fared academically. We compared the average overall GPA of students completing the program who switched to the CS major (3.11) with the average GPA of students who switched to the CS major without participating in the program (3.07). These numbers assure us that one potentially negative outcome of the program has not occurred: We have not enticed students into the major who are not capable of doing the work. They aren't just riding a temporary wave of excitement from the summer program and then flaming out.

\section{NEXT STEPS}

Through National Science Foundation funding, the program will be run five times, each summer through 2019. More complete results will be reported in several more years, when we know graduation and retention rates. Following that, we hope to sustain the program via institutional funds or other sources (talks are already under way with the administration, with positive indications so far: the program helps retain students, and administrators like that). Of course, the program is not free, but neither is it prohibitively expensive. The annual budget for the program is about $\$ 7500$. About $\$ 2000$ of that is for the stipends for the participants, with the bulk of the remainder covering food and lodging for the participants as well as payments for the two student assistants. The faculty donate their time.

We will continue to monitor the numbers of undeclared students, and if they do not rise, we will continue with our expanded invitation list (including selected biology and business majors) in subsequent years.

\section{CONCLUSIONS \& LESSONS LEARNED}

The program has been a great success, based on our "rate of return" on new majors, new minors, and students simply taking another CS course. The program is fun for the students and for the faculty; hopefully word will spread via the students not just about the program but about the possibilities of CS. In addition, it can help show the participants, who may not have encountered many computer scientists up to this point in their education, that we (faculty and students in CS) are people too and maybe this can help break down some of the popular misconceptions of our field, making it easier to achieve "CS For All”.

We have presented a 1-week summer residential program, held just before classes begin, that introduces undeclared rising sophomores (and a few incoming freshmen) to the wonders of CS. The program includes interactive, faculty-led sessions both with and without a computer as well as panels of alumni, students, and faculty. The goal of the program is to expose more students, especially those with relevant aptitudes, to the field of CS as a whole. The results have been very positive and gratifying, with over $30 \%$ of participants declaring a CS major, 5.13\% minoring in CS, and most of the rest taking at least one more course in the field. We hope to continue the program indefinitely, as long as it continues to work, and we encourage other institutions to try similar programs.

\section{ACKNOWLEDGMENTS}

This work was supported by NSF grant 1432198 . We would also like to thank the anonymous referees for their comments.

\section{REFERENCES}

[1] R. H. Bork, A. K. Mayer, J. Pretlow, H. D. Wathington, M. J. Weiss. 2012 Bridging the gap: An impact study of eight developmental summer bridge programs in Texas. New York: National Center for Postsecondary Research.

[2] MaryAnne L. Egan and Timoth Lederman. 2011. The impact of IMPACT: assessing students' perceptions after a day of computer exploration. In Proceedings of the 16th annual joint conference on Innovation and technology in computer science education (ITiCSE '11). ACM, New York, NY, USA, 318322.

[3] Gallup Poll. 2016. Trends in the State of Computer Science in U.S. K-12 Schools.

[4] E.G. Helm, J.E. Parker, M.C. Russell. Education and career paths of LSU's summer science program students from 1985 to 1997. Academic Medicine: April 1999. Journal Article: PDF Only.

[5] Chris Johnson. 2017. Toward Computational Making with Madeup. In In Proceedings of the 2017 ACM SIGCSE Technical Symposium on Computer Science Education (SIGCSE '17). ACM, pp. 297-302.

[6] Bill Manaris, Andrew R. Brown. 2014. Making Music with Computers Creative Programming in Python, CRC Press.

[7] Dina G. Markowitz. Journal of Science Education and Technology September 2004, Volume 13, Issue 3, pp 395-407. Evaluation of the Long-Term Impact of a University High School Summer Science Program on Students' Interest and Perceived Abilities in Science.

[8] Alexander Repenning, David Webb, Andri Ioannidou. 2010. Scalable Game Design and the Development of a Checklist for Getting Computational Thinking into Public Schools. In Proceedings of the 41st ACM technical symposium on Computer Science Education (SIGCSE '10). ACM, pp. 265-269.

[9] Rahman Tashakkori , Barry L. Kurtz, Dolores A. Parks, James B. Fenwick, Jr., Alice A. McRae, Early participation of CS students in research, Proceedings of the 42nd ACM technical symposium on Computer science education, March 09-12, 2011, Dallas, TX, USA [doi $>10.1145 / 1953163.1953185]$ 